\title{
The diagnostic value of serum creatinine and cystatin $c$ in evaluating glomerular filtration rate in patients with chronic kidney disease: a systematic literature review and meta-analysis
}

\author{
Xilian Qiu ${ }^{1, *}$, Chunyong Liu ${ }^{2, *}$, Yuqiu $\mathrm{Ye}^{3, *}$, Huiqun $\mathrm{Li}^{3}$, Yanbing Chen ${ }^{4}$, Yongmei \\ Fu $^{3}$, Zhenjie Liu ${ }^{2}$, Xianzhang Huang ${ }^{2}$, Yunqiang Zhang ${ }^{5}$, Xueyuan Liao ${ }^{5}$, Hongyong \\ Liu $^{5, *}$, Wenbo Zhao ${ }^{3}$ and Xun Liu ${ }^{5,3}$ \\ ${ }^{1}$ Department of Laboratory Medicine, The First Affiliated Hospital of Sun Yat-sen University, Guangzhou, China \\ ${ }^{2}$ Department of Laboratory Medicine, The Second Affiliated Hospital of Guangzhou University of Traditional Chinese Medicine, \\ Guangzhou, China \\ ${ }^{3}$ Department of Nephrology, The Third Affiliated Hospital of Sun Yat-sen University, Guangzhou, China \\ ${ }^{4}$ Medical genetic center, Guangdong Women And Children Hospital, Guangzhou, Guangdong, China \\ ${ }^{5}$ Division of Nephrology, The 3rd Affiliated Hospital of Sun Yat-sen University, Yuedong Hospital, Meizhou, China \\ *These authors contributed equally to this work
}

Correspondence to: Xun Liu, email: naturestyle@163.com

Wenbo Zhao, email: bobo800101@foxmail.com

Hongyong Liu, email: 13823850589@139.com

Keywords: creatinine, cystatin C, glomerular filtration rate, meta-analysis

Received: June 07, $2017 \quad$ Accepted: July 30, $2017 \quad$ Published: August 16, 2017

Copyright: Qiu et al. This is an open-access article distributed under the terms of the Creative Commons Attribution License 3.0 (CC BY

$3.0)$, which permits unrestricted use, distribution, and reproduction in any medium, provided the original author and source are credited.

\section{ABSTRACT}

Background: Serum biomarkers, such as serum creatinine ( $\mathrm{SCr}$ ) and serum cystatin C (SCysC), have been widely used to evaluate renal function in patients who have chronic kidney disease (CKD).

Objective: This article aims to assess the value of determining $\mathrm{SCr}$ and $\mathrm{SCysC}$ levels in patients that have long-term kidney disease. Approaches: MEDLINE, EmBase, the Cochrane Library and other databases were searched using both MeSH terms and text words to collect research that assessed the diagnostic value of using $\mathrm{SCr}$ and SCysC to evaluate Glomerular Filtration Rate (GFR) in patients with CKD. Data were converted into fourfold tables. Summary Receiver Operating Characteristic Curves and meta-analyses were accomplished via Meta-Disc version 1.4.

Results: In total, 21 relevant articles involving 3112 study subjects were included in our review. Results showed that the collective sensitivity for SCr and SCysC was 0.77 (95\% CI: $0.69-0.84)$ and 0.87 (95\% CI: $0.82-0.91)$, respectively. The pooled specificity for SCr and SCysC was 0.91 (95\% CI: 0.86-0.94) and 0.87 (95\% CI: 0.82-0.91), respectively. Subgroup analyses demonstrated that when GFR cutoff values are set to $60\left(\mathrm{ml} / \mathrm{min} / 1.73 \mathrm{~m}^{2}\right)$, the pooled sensitivity is $0.94(95 \% \mathrm{CI}$ : 0.90-0.96) for SCysC and 0.75 (95\% CI: 0.68-0.82) for SCr.

Conclusions: The diagnostical accuracy for impaired kidney function favors SCysC. Confidence intervals for the pooled sensitivity and specificity for $\mathrm{SCr}$ and SCysC overlap. However, SCysC is more sensitive for estimating GFR than SCr when GFR cut-off values are set to $60\left(\mathrm{ml} / \mathrm{min} / 1.73 \mathrm{~m}^{2}\right)$.

\section{INTRODUCTION}

CKD, as well as end stage renal disease (ESRD), presents serious risks to human health. Worldwide, the incidence and prevalence of CKD dramatically increases with aging $[1,2]$. As a progressive disease, CKD in many cases leads to ESRD. Accurate and convenient evaluation of renal function is important for both healthy populations 
and patients with $\mathrm{CKD}$, especially those with mild to moderate decreased renal function. Early initiation of treatment in CKD patients has shown that it is possible to delay or even prevent the frequency and severity of adverse outcomes. Hence, early stage prognosis of CKD is required for early initiation of treatment to help patients, in particular, those at greatest risk for progression. GFR is regarded as a significant indicator for kidney surgery, and this measurement is considered to be the gold standard for evaluating renal disease. In addition, GFR is utilized as an independent risk factor affecting cardiovascular function [3]. It was found that a low GFR is associated with increased mortality, cardiovascular events and hospitalizations. Hence, GFR acts as an important indicator in the diagnosis of patients, as well as in clinical management.

In addition to $\mathrm{SCysC}$, urine sediment abnormalities, and albuminuria, SCr has also been used as a traditional endogenous biomarker for renal function. Researchers commonly utilize the clearance rate of exogenous filtration markers in evaluating GFR, including radioactive materials such as inulin, ${ }^{125} \mathrm{I}$-iothalamate, iohexol, ${ }^{99 \mathrm{~m}} \mathrm{Tc}$ DTPA, ${ }^{51} \mathrm{Cr}$-EDTA, among others. Although incompatible with routine monitoring, experts use these materials in professional research and even in clinical trials [4-7].

Estimating GFR is a method used to measure endogenous substances in the blood. SCr is indicated in many studies as having less sensitivity for kidney failure, especially in patients with minor kidney dysfunction and in older CKD patients in whom kidney deficiency is often under-recognized. Recently, in accordance with these new findings, SCysC has been proposed as a filtration marker of GFR to replace SCr. Many studies [8-11] recently demonstrated that SCysC is a more sensitive serum marker than $\mathrm{SCr}$ for evaluating renal glomerular filtration function damage; however, there are some differing points of view [12]. To the best of our knowledge, only Van Pottelbergh, et al. [13] completed a systematic review in 2010 that tried to investigate and ascertain the best process to provide measurements of renal function. However, they could not clearly define which methods were most accurate at evaluating kidney function in people with $\mathrm{CKD}$ as they examined only a small number of prospective studies and populations, and only included articles written in English. There has been no update until 2010, when several groups compared the Modification of Diet in Renal Disease (MDRD) and Cockcroft-Gault (CG) formulas and other equations, such as the Chronic Kidney Disease Epidemiology Collaboration (CKD-EPI) equation [14-18]. Therefore, an updated heterogeneous meta-analysis including the Chinese population is needed to better evaluate kidney function.

\section{MATERIALS AND METHODS}

\section{Literature search strategy}

We undertook a systematic meta-analysis in accordance with Preferred Reporting Items for Systematic
Reviews and Meta-analyses (PRISMA) guidelines (see Supplementary Table 2) and the Standards for Reporting of Diagnostic Accuracy (STARD) guidelines. We searched population-based studies and different cross-sectional studies that included patients with CKD. In detail, we searched MEDLINE (via PubMed), the Cochrane Library, EmBase, Chinese National Knowledge Infrastructure and the Chinese Biomedical Literature Database, as well as other databases and relevant conference meetings from inception to 13th, Feb. 2017, using the following keywords and corresponding medical subject heading: "Chronic kidney disease", "CKD”, "end stage renal disease”, "ESRD”, “cystatin C", "SCysC”, “creatinine”, "SCr", "glomerular filtration rate”, "GFR”,", “diagnosis test”, "sensitivity”, "specificity”, and synonyms. In the search strategy, subject terms and keywords were applied in combination. Searches using other engines such as Google Scholar on the internet were performed in supplement. No restriction was placed on language or publication forms. Authors of resource studies were contacted by email and telephone for help if examined reports lacked details or enough applicable information.

Two independent reviewers (Chunyong Liu and Huiqun Li) evaluated the articles, and screened titles and abstracts to assess eligibility and remove duplicates. Discrepancies were resolved by discussion among all authors. Search strategies of all databases could be found in Supplementary Table 1.

\section{Study selection criteria}

We excluded studies as follows: publications containing the same information; studies with inadequate facts; personal opinions, meetings, reviews and meta-analysis articles; animal and cell studies; studies including fewer than 30 people. Diagnostic randomized controlled trials (D-RCT) were also not included. Studies were considered suitable for inclusion if they met criteria including: (a) studies investigating the use of $\mathrm{SCr}$ and $\mathrm{SCysC}$ when calculating GFR in patients with CKD; (b) studies providing statistical data such as extracted population characteristics, total size of research conducted, sensitivity and specificity, cut-off values, true and false positive and negative data or if such data could be extracted by reading context; (c) the search attempted to identify diagnostic accuracy test (DAT); (d) the use of gold standard tests, including measurements of inulin, ${ }^{125} \mathrm{I}$-iothalamate, ${ }^{99 \mathrm{~m}} \mathrm{Tc}-\mathrm{DTPA}$, iohexo 和 $1,{ }^{51} \mathrm{Cr}$-EDTA [19-21].

\section{Detection method}

For $\mathrm{SCr}$ and $\mathrm{SCysC}$ detection, all clinical methods were included. The testing processes for SCysC were particle-enhanced nephelometric immunoassay (PENIA) and particle-enhanced turbidimetric immunoassay (PETIA) $[22,23]$. The detection methods for SCr were the enzymatic method and the Jaffé method [24]. 


\section{Data extraction and literature quality assessment}

Independent reviews by Chunyong Liu and Huiqun Li highlighted other possible studies in accordance with the above described exploration approach. Both reviews and summaries of every article were studied repeatedly to be sure inclusion criteria were met.

In cases of several publications focusing on the same research, we included the one with the largest and most detailed data only. Any disagreement between the two reviewers was resolved with the help of a third reviewer (Xilian Qiu).

Data were extracted in accordance with a standardized form, and controversies surrounding differing data were resolved by consensus. Extracted study characteristics were country of origin, year of publication, study size, age, gender prevalence of $\mathrm{CKD}$, kind of risk and adjusted confounding factors. Summary specificity (SPE), summary sensitivity (SEN), summary positive and summary negative predictive values ( \pm PVs), summary positive and summary negative likelihood ratios ( \pm LRs), summary receiver operating characteristic (SROC) curves, area under the summary receiver operating characteristic (SAUC), and diagnostic tests combined odds ratio (DOR) were also determined. One author (Chunyong Liu) entered the data separately into the software RevMan version 5.3, Stata software version 14.0 and MetaDisc version 1.4. A second author (Huiqun Li) and a third author (Xilian Qiu) independently checked the data entry.

Two investigators (Chunyong Liu and Huiqun Li) independently evaluated the quality of studies in this metaanalysis via the quality evaluation of diagnostic accuracy studies-2 (QUADAS-2) system, which was described by Whiting, P. $[25,26]$. Criteria consisted of four components (patient selection, index test, reference standard, flow and timing), and was analyzed by the RevMan 5.3 software. Each component was evaluated for risk of bias, and the first three components are also evaluated in terms of applicability. Signaling questions were involved to help judge the risk of bias. The quality assessment of the involved studies was independently carried out by Chunyong Liu and Huiqun Li.

\section{Synthesis and analysis of data}

Meta-analysis was carried out by the software RevMan version 5.3, and Meta-Disc version 1.4. Publication bias analysis was performed using Stata 14.0 (Stata Corp, College Station, TX, USA). When a fourfold table contained a cell with a value of 0 , the calculations were corrected with the addition of 0.5 in the cell. Studies containing two cells with the value of 0 were not included in the analysis [26]. Each document was summarized by SPE, SEN, \pm PVs, \pm LRs for diagnostic tests, and also analyzed for heterogeneity with the $\chi^{2}$ test. This was evaluated using the $\mathrm{I}^{2}$ method, and significant study heterogeneity was considered when $\mathrm{I}^{2}>50 \%$. $\mathrm{I}^{2}$ values between 25 and $50 \%$ were deemed to show modest heterogeneity and $\mathrm{I}^{2}$ values $<25 \%$ were thought to indicate low heterogeneity. Clinical utility of SCysC and SCr for estimated GFR (eGFR) was evaluated by a Fagan plot. We drew the SROC curve based on the literature included in this study, and calculated the zone under the receiver operating characteristic curves. All results are presented with $95 \%$ confidence intervals (CI) [27].

\section{RESULTS}

\section{Characteristics of the literature search and screening}

A flow chart of the literature search and literature screening created using RevMan 5.3 is shown clearly in Figure 1. The original literature search identified 1190 studies. Of these, 1097 studies were excluded due to duplication or lack of accordance with inclusion criteria, and 70 studies were eliminated after reading titles and abstracts carefully. In the end, only 33 publications met the inclusion criteria. We tried to contact 11 corresponding authors of 12 studies to obtain details for the fourfold table or to complete information, but were unable to make contact or obtain useful information. Finally, 12 publications were eliminated due to incomplete fourfold table information, and 21 publications were used for the present research. Among these, 17 were published in English, and four were written in Chinese. All studies focused on the diagnostic test for GFR values via $\mathrm{SCr}$ and SCysC.

General information was extracted from 21 literature sources comprising 3112 patient cases. The number of males was generally slightly higher than females. For the assessment of renal function, the cut-off values of $\mathrm{SCysC}$ and $\mathrm{SCr}$ were $0.81-1.74 \mathrm{mg} / \mathrm{L}$ and $75.1-149.0 \mu \mathrm{mol} / \mathrm{L}$, respectively. Four literature sources made no reference to these indicators. The cut-off value of measured GFR tested by the gold standard was $60-90 \mathrm{ml} / \mathrm{min} / 1.73 \mathrm{~m}^{2}$. The main characteristics of the literature are shown in Table 1 and Table 2.

\section{Quality assessment of the included literature}

QUADAS-2 results are shown in Figure 2 and Figure 3. Regarding the risk of bias, there were six studies that fulfilled all QUADAS-2 criteria. In eight studies, there was uncertain risk of bias in patient selection, and two studies showed a high risk of bias in patient selection. Three studies showed uncertain risk of bias in the index test, and two studies showed unclear risk of bias in the reference standard. Five studies showed uncertain risk of bias in the flow and timing. Some studies [16, 18, 22, 23, 25] enrolled mostly female or male patients, who might not be representative of the target population, and so potential spectrum bias existed.

The results of the quality assessment for the 21 included studies are shown in Figure 2. Generally, most of the included studies met the quality criteria. 
Figure 3 shows the integration of the methodological quality of included papers based on the foundation of reviewers' assessments with regard to the four areas evaluating the risk of bias and the three domains evaluating applicability issues for the QUADAS-2 checklist for each study. Specifically, studies with a small bias risk or small applicability issues are highlighted in green and the studies with a high risk of applicability or bias issues are in red. Studies where risks of bias or applicability issues could not be assessed properly are indicated in yellow.

\section{Meta-analysis results}

All included studies investigated the diagnostic accuracy of both $\mathrm{SCr}$ and SCysC in predicting $\mathrm{CKD}$ diseases. In total, 21 studies were included and 17 of them provided complete data for this meta-analysis. Regarding the diagnostic $2 \times 2$ table, all 21 studies provided the value of SCysC, while 17 studies provided the value of SCr.

The pooled diagnostic accuracy of SCysC and $\mathrm{SCr}$ were tested. Across all settings, the pooled sensitivity for $\mathrm{SCr}$ and SCysC was 0.77 (95\% CI: 0.69-0.84) and 0.87 (95\% CI: 0.82-0.91), respectively, and the pooled specificity for $\mathrm{SCr}$ and $\mathrm{SCysC}$ was 0.91 (95\% CI: 0.86-0.94) and 0.87 (95\% CI: 0.82-0.91), respectively. CIs for pooled sensitivity and specificity for $\mathrm{SCr}$ and SCysC overlap. Analysis results of SCysC and SCr did not show that $\mathrm{SCysC}$ had the highest pooled sensitivity and specificity. Figure 4A and Figure 4B below shows the sensitivity and specificity of SCysC and $\mathrm{SCr}$, respectively. Results for the forest plot of positive LR and negative LR, the forest plot of the DOR in evaluating eGFR, and the SROC Curve for SCr and SCysC are shown from Supplementary Figure 1 to Supplementary Figure 9.

\section{Subgroup analysis}

The pooled diagnostic accuracy of SCysC and $\mathrm{SCr}$ using different GFR cut-off values of $60\left(\mathrm{ml} / \mathrm{min} / 1.73 \mathrm{~m}^{2}\right)$ and $90\left(\mathrm{ml} / \mathrm{min} / 1.73 \mathrm{~m}^{2}\right)$ were tested. GFR cut-off values of $60\left(\mathrm{ml} / \mathrm{min} / 1.73 \mathrm{~m}^{2}\right)$, from Figure $5 \mathrm{~A}$, revealed a pooled sensitivity for SCysC of 0.94 (95\% CI: 0.90-0.96), and a pooled specificity for SCysC of 0.86 (95\% CI: 0.78-0.91). Using GFR cut-off values of $60\left(\mathrm{ml} / \mathrm{min} / 1.73 \mathrm{~m}^{2}\right)$, shown in Figure 5B, pooled sensitivity for $\mathrm{SCr}$ was 0.75 (95\% CI: $0.68-0.82)$, and pooled specificity for $\mathrm{SCr}$ was 0.88 (95\% CI:
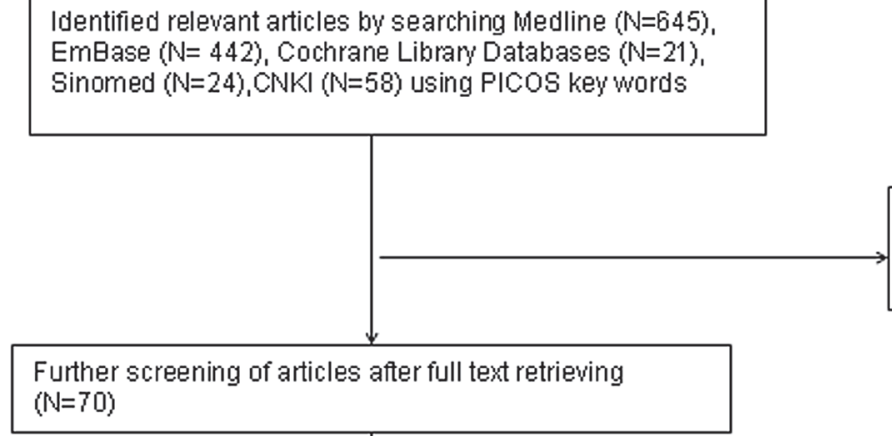

Eliminating duplicate articles via Reference Manger NoteExpress, improper articles after reading titles, abstracts, key words $(\mathrm{N}=870)$

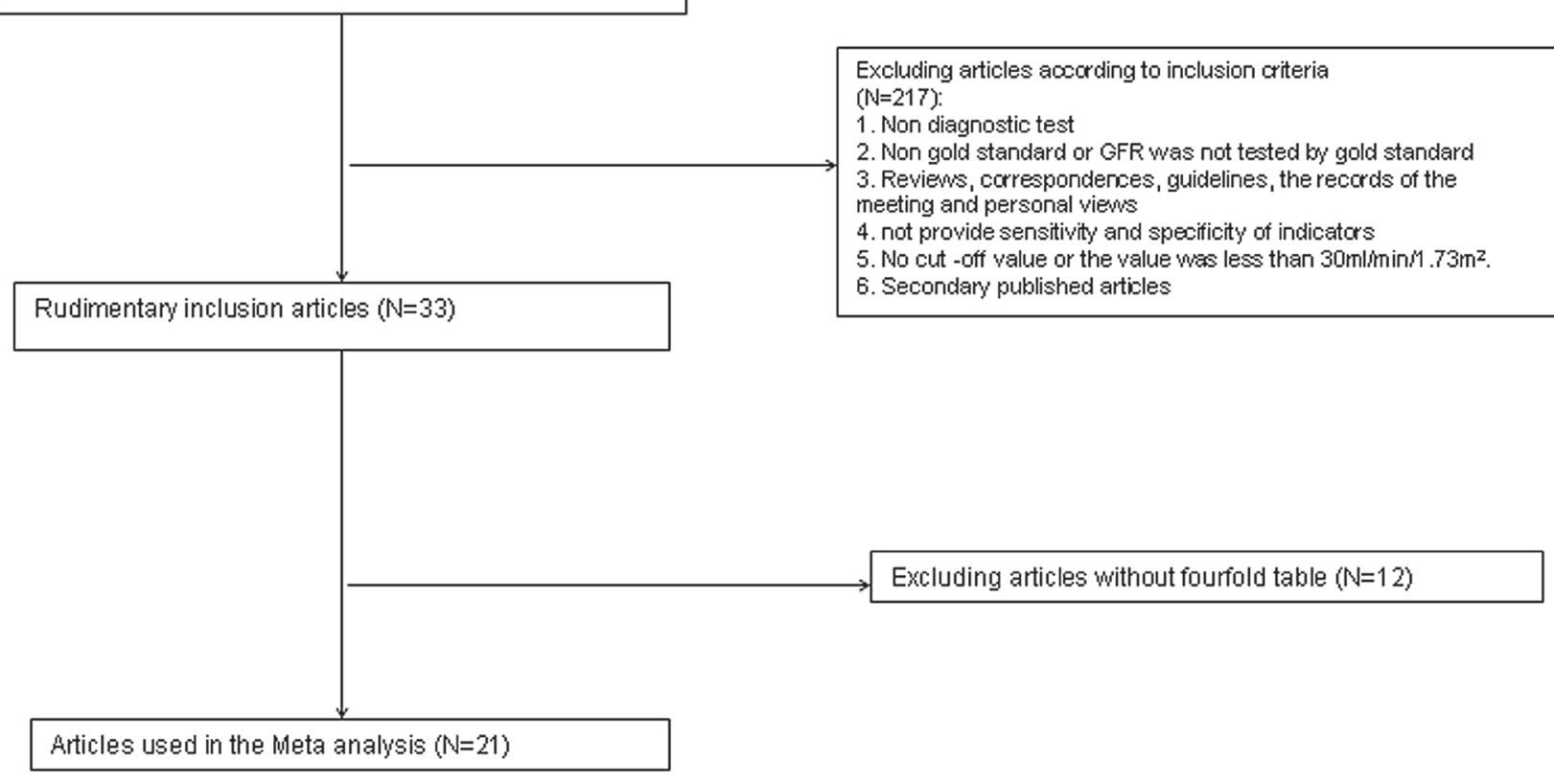

Figure 1: Flowchart representing study selection for systematic review of SCr andSCysC as a diagnostic tool for renal CKD evaluation. 
Table 1: Main characteristics of 21 studies selected for a meta-analysis of the diagnostic value of $\mathrm{SCr}$ and SCysC in the evaluation of GFR

\begin{tabular}{|c|c|c|c|c|c|c|c|}
\hline Author Year & $\begin{array}{l}\text { Country } \\
\text { of residence }\end{array}$ & $\begin{array}{l}\text { Study Participants } \\
\text { NO. of cases/NO of } \\
\text { patients }\end{array}$ & Average age & Male (\%) & Golden Stanard & Detection method of Cys C & Detection method of $\mathrm{Cr}$ \\
\hline Burkhardt, H 2002 [41] & Germany & 30 & 75.4 & 50 & Inulin clearance & Cys C PETIA assay & Cr Jaffé method \\
\hline Chantrel, F 2000 [42] & France & 161 & 39 & 49.1 & inulin & Cys C PENIA assay & Cr Enzyme method \\
\hline Donadio, C 2010 [43] & Italy & 295 & 52.4 & 53.6 & 99mTc-DTPA & Cys C PENIA assay & Cr Jaffé method \\
\hline Donadio, C 2012 [44] & Italy & 367 & 52.7 & 46.9 & 99mTc-DTPA & PENIA \& PETIA assay & Cr Jaffé method \\
\hline Filler, G 2002 [45] & Canada/Germany & 225 & / & 59.5 & 51Cr-EDTA & Cys C PENIA assay & Cr Enzyme method \\
\hline Funda Aydin 2015 [46] & Turkey & 84 & 61 & 70.2 & 99mTc-DTPA & PENIA assay & Cr Jaffé method \\
\hline Harmoinen, A P 1999 [47] & Finland & 51 & I & 51 & 51Cr-EDTA & Cys C PETIA assay & / \\
\hline Hojs, R 2006 [48] & Slovenia & 164 & 57.5 & 52.4 & 51Cr-EDTA & Immunonephelometric assay & Cr Jaffé method \\
\hline Kyhse-Andersen, J 1994 [49] & Denmark/Sweden & 51 & I & 53 & / & Cys C PETIA assay & Cr Enzyme method \\
\hline Li Hai-xia 2005 [50] & China & 51 & 54 & 49 & 99m Tc-DTPA & Cys C PENIA assay & Cr Jaffé method \\
\hline Li Hai-xia 2006 [51] & China & 265 & 53 & 55.5 & 99m Tc-DTPA & Cys C PENIA assay & Cr Jaffé method \\
\hline Li Ping 2005 [52] & China & 71 & I & / & 99m Tc-DTPA & Cys C PETIA assay & Cr Jaffé method \\
\hline Macisaac, R J 2007 [53] & Australia & 251 & 60 & 61 & 99mTc-DTPA & Cys C PENIA assay & Cr Jaffé method \\
\hline Newman, D J 1995 [54] & Sweden & 206 & / & 55.8 & 51Cr-EDTA & Cys C PETIA assay & Cr Jaffé method \\
\hline Pöge, U 2006 [55] & Germany & 105 & 49.5 & 58.1 & 99mTc-DTPA & Immunonephelometric assay & Cr Jaffé method \\
\hline Rigalleau, V 2008 [56] & France & 124 & 62 & 62.9 & 51Cr-EDTA & Cys C PENIA assay & Cr Jaffé method \\
\hline Spanaus, K S 2010 [57] & Germany, Austria, Italy & 227 & 45.7 & 67.8 & iohexol & Cys C PENIA assay & Cr Jaffé method \\
\hline Stickle, D 1998 [58] & USA & 34 & I & NA & inulin clearance & Cys C PETIA assay & picric acid assay \\
\hline Van Den Noortgate, N J 2002 [59] & Belgium & 48 & 84.4 & 35 & 51Cr-EDTA & Cys C PETIA assay & Cr Jaffé method \\
\hline Wang Hong-ru 2010 [60] & China & 76 & 55.01 & 44.7 & 99m Tc-DTPA & Cys C PETIA assay & Cr Enzyme method \\
\hline Zhou You 2008 [61] & China & 186 & 56.13 & 53.2 & 99m Tc-DTPA & Cys C PENIA assay & Cr Jaffé method \\
\hline
\end{tabular}

$\mathrm{CKD}=$ chronic kidney disease; $\mathrm{SCr}=$ serum creatinine; $\mathrm{SCysC}=$ serum cystatin $\mathrm{C} ; \mathrm{GFR}=$ glomerular filtration rate; $\mathrm{mGFR}=$ measured GFR; PETIA = particle-enhanced turbidimetric immunoassay; PENIA = particle-enhanced nephelometric immunoassay; NA or " $"$ " = not applicable.

0.83-0.92). Diagnostic accuracy of impaired renal function favors SCysC. SCysC is more sensitive for estimating GFR than $\mathrm{SCr}$ when the GFR cut-off values are set as $60(\mathrm{ml} /$ $\left.\mathrm{min} / 1.73 \mathrm{~m}^{2}\right)$. The GFR cut-off values of $90(\mathrm{ml} / \mathrm{min} / 1.73$ $\mathrm{m}^{2}$ ), from Figure $6 \mathrm{~A}$, resulted in a pooled sensitivity for SCysC of 0.83 (95\% CI: 0.74-0.89) and a pooled specificity for SCysC of 0.90 (95\% CI: 0.82-0.95). From Figure 6B, pooled sensitivity for SCr was 0.79 (95\% CI: 0.62-0.90), and pooled specificity for SCr was 0.95 (95\% CI: 0.85-0.98).

\section{Heterogeneity analysis and publication bias analysis}

Heterogeneity analysis values for each research publication are displayed in Figure 7A and Figure 7B. Heterogeneity analysis regarding $\mathrm{SCr}$ and $\mathrm{SCysC}$ detection showed that there was no heterogeneity for most studies. Deeks funnel plot asymmetry test for all examinations showed no publication bias. For SCysC detection, $P=0.89$ (Figure 8A), and for SCr detection, $P=0.26$ (Figure 8B).

\section{SROC curves}

SROC curves of the diagnostic value of GFR via $\mathrm{SCr}$ and SCysC are shown in Supplementary Figure 6,
Supplementary Figure 7. SROC curve of the diagnostic value of GFR via cystatin $\mathrm{C}$ and creatinine were shown in Figure 9. The pattern of SCr and SCysC displayed the nonscatter 'shoulder arm' shape, indicating a low possibility of threshold effects in the adopted literature. There was no significant difference when comparing the AUC of $\mathrm{SCr}$ and SCysC because the confidence intervals overlap (AUC $\mathrm{SCr}=0.92$ (95\% CI: 0.89-0.94), AUC SCysC $=0.93(95 \%$ CI: $0.91-0.95)$. Posttest probability was calculated with a presumed pretest probability of 50\% via Fagan's plot. We described diagnostic values using Fagan's nomogram, which were SCysC and SCr for eGFR (Figure 10A, 10B). When $50 \%$ was selected as the pre-test probability, the data showed the post-test probability increased to $94 \%$ for the diagnostic value of SCysC, while the post-test probability increased only to $89 \%$ for the diagnostic value of $\mathrm{SCr}$, indicating that the diagnostic value of SCysC is better than that of SCr.

\section{DISCUSSION}

$\mathrm{SCr}$, SCysC and endogenous creatinine clearance rates were utilized as endogenous indicators to estimate GFR in the clinical setting. In the estimation of GFR, ideal endogenous blood substances incorporate the following 
Table 2: The cut-off value of GFR, SCysC, SCr, fourfold table data, sensitivity and specificity index of the adopted literature

\begin{tabular}{|c|c|c|c|c|c|c|c|c|c|c|}
\hline Author Year & $\begin{array}{c}\text { The cut-off } \\
\text { value of GFR } \\
(\mathrm{mL} / \mathrm{min} / \\
\left.1.73 \mathrm{~m}^{2}\right)\end{array}$ & Cut-off & & TP & FP & FN & $\mathbf{T N}$ & $\mathbf{r}$ & Sensitivity (\%) & Specificity (\%) \\
\hline \multirow{2}{*}{ Burkhardt, H 2002 [41] } & \multirow{2}{*}{70} & Cystatin C & 1.63 & 7 & 5 & 5 & 13 & / & 0.58 & 0.72 \\
\hline & & Serum creatinine & 82 & 11 & 7 & 1 & 11 & l & 0.92 & 0.61 \\
\hline \multirow{2}{*}{ Chantrel, F 2000 [42] } & \multirow{2}{*}{90} & Cystatin C & 0.9 & 58 & 7 & 19 & 77 & 0.7 & 0.75 & 0.92 \\
\hline & & Serum creatinine & 1.1 & 55 & 5 & 22 & 79 & 0.74 & 0.71 & 0.94 \\
\hline \multirow{2}{*}{ Donadio, C 2010 [43] } & \multirow{2}{*}{90} & Cystatin C & 0.95 & 225 & 3 & 39 & 28 & 0.93 & 0.85 & 0.9 \\
\hline & & Serum creatinine & 105 & / & l & l & l & l & / & / \\
\hline \multirow{2}{*}{ Donadio, C 2012 A [44] } & \multirow{2}{*}{90} & Cystatin C & 0.95 & 222 & 1 & 6 & 28 & 0.91 & 0.66 & 0.97 \\
\hline & & Serum creatinine & 105 & 219 & 1 & 9 & 28 & 0.94 & 64.7 & 96.5 \\
\hline \multirow{2}{*}{ Funda Aydin 2015 [46] } & \multirow{2}{*}{90} & Cystatin C & 1.02 & 33 & 11 & 2 & 38 & 0.90 & 0.93 & 0.78 \\
\hline & & Serum creatinine & 118 & 39 & 6 & 6 & 33 & 0.80 & 0.86 & 0.85 \\
\hline \multirow{2}{*}{ Filler, G 2002 [45] } & \multirow{2}{*}{90} & Cystatin C & 1.11 & 60 & 8 & 15 & 142 & -0.76 & 0.8 & 0.95 \\
\hline & & Serum creatinine & 83 & 26 & 8 & 49 & 142 & -0.5 & 0.35 & 0.95 \\
\hline \multirow{2}{*}{$\begin{array}{l}\text { Harmoinen, A P } 1999 \\
\text { [47] }\end{array}$} & \multirow{2}{*}{80} & Cystatin C & 1.2 & 14 & 6 & 3 & 28 & 0.77 & 0.82 & 0.82 \\
\hline & & Serum creatinine & 104 & 6 & 2 & 10 & 33 & 0.56 & 0.038 & 0.94 \\
\hline \multirow{2}{*}{ Hojs, R 2006 [48] } & \multirow{2}{*}{60} & Cystatin C & 1.74 & 67 & 22 & 4 & 71 & 0.79 & 0.95 & 0.77 \\
\hline & & Serum creatinine & 149 & 60 & 6 & 26 & 72 & / & 0.7 & 0.92 \\
\hline \multirow{2}{*}{$\begin{array}{l}\text { Kyhse-Andersen, } \\
1994 \text { [49] }\end{array}$} & \multirow{2}{*}{80} & Cystatin C & I & 19 & 2 & 5 & 25 & I & 0.79 & 0.93 \\
\hline & & Serum creatinine & / & 14 & 2 & 10 & 25 & I & 0.58 & 0.93 \\
\hline \multirow{2}{*}{ Li Hai-xia 2005 [50] } & \multirow{2}{*}{80} & Cystatin C & 1 & 13 & 14 & 1 & 23 & 0.74 & 0.93 & 0.62 \\
\hline & & Serum creatinine & 113 & 12 & 15 & 2 & 22 & 0.65 & 0.48 & 0.96 \\
\hline \multirow{2}{*}{ Li Hai-xia 2006 [51] } & \multirow{2}{*}{80} & Cystatin C & 1.17 & 163 & 38 & 12 & 52 & 0.66 & 0.93 & 0.58 \\
\hline & & Serum creatinine & 107 & 140 & 12 & 35 & 78 & 0.53 & 0.8 & 0.87 \\
\hline L: Di. & 80 & Cystatin C & 1.43 & 48 & 2 & 3 & 18 & 0.9 & 0.94 & 0.9 \\
\hline Li Fing $2003[52]$ & 80 & Serum creatinine & 112 & 46 & 4 & 5 & 16 & 0.85 & 0.92 & 0.8 \\
\hline Macisaac, R J 2007 & 60 & Cystatin C & 0.81 & 53 & 20 & 1 & 177 & 0.81 & 0.98 & 0.9 \\
\hline [53] & 60 & Serum creatinine & 90 & 54 & 26 & 11 & 161 & 0.72 & 0.83 & 0.86 \\
\hline N) & 72 & Cystatin C & 1.25 & 60 & 6 & 24 & 116 & 0.81 & 0.71 & 0.95 \\
\hline ] & & Serum creatinine & 110 & 44 & 10 & 40 & 112 & 0.5 & 0.52 & 0.92 \\
\hline D̈̈ L & 60 & Cystatin C & 1.41 & 84 & 1 & 7 & 13 & 0.86 & 0.92 & 0.93 \\
\hline $10 \mathrm{ge}, \mathrm{C} 2000$ [JJ] & & Serum creatinine & / & l & I & / & l & / & I & / \\
\hline 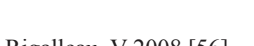 & 60 & Cystatin C & 1.56 & 70 & 6 & 6 & 42 & 0.82 & 0.93 & 0.88 \\
\hline 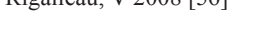 & 00 & Serum creatinine & 148 & / & l & / & l & 0.79 & / & l \\
\hline Sponour V S $2010[57]$ & 00 & Cystatin C & 0.91 & 147 & 25 & 8 & 47 & 0.87 & 0.95 & 0.76 \\
\hline 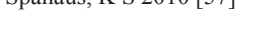 & & Serum creatinine & 91 & 143 & 26 & 12 & 46 & 0.85 & 0.92 & 0.64 \\
\hline & & Cystatin C & 1.4 & 20 & 0 & 3 & 11 & 0.87 & 0.87 & 1 \\
\hline Strckle, D 1998 [38] & 90 & Serum creatinine & 79.5 & 21 & 1 & 2 & 10 & 0.9 & 0.91 & 0.9 \\
\hline Van Den Noortgate, N J & 80 & Cystatin C & 1.09 & 28 & 0 & 11 & 9 & 0.62 & 0.72 & 1 \\
\hline 2002 [59] & & Serum creatinine & 75.1 & 22 & 0 & 17 & 9 & 0.68 & 0.56 & 1 \\
\hline Wang Hong-ru 2010 & 00 & Cystatin C & 1.35 & 44 & 2 & 18 & 12 & -0.81 & 0.71 & 0.86 \\
\hline [60] & & Serum creatinine & / & l & I & / & I & -0.73 & I & / \\
\hline 77b Y 2000 [61] & 80 & Cystatin C & I & 114 & 27 & 9 & 36 & -0.66 & 0.96 & 0.57 \\
\hline 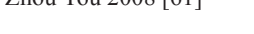 & & Serum creatinine & 1 & 99 & 8 & 24 & 55 & -0.52 & 0.8 & 0.87 \\
\hline
\end{tabular}




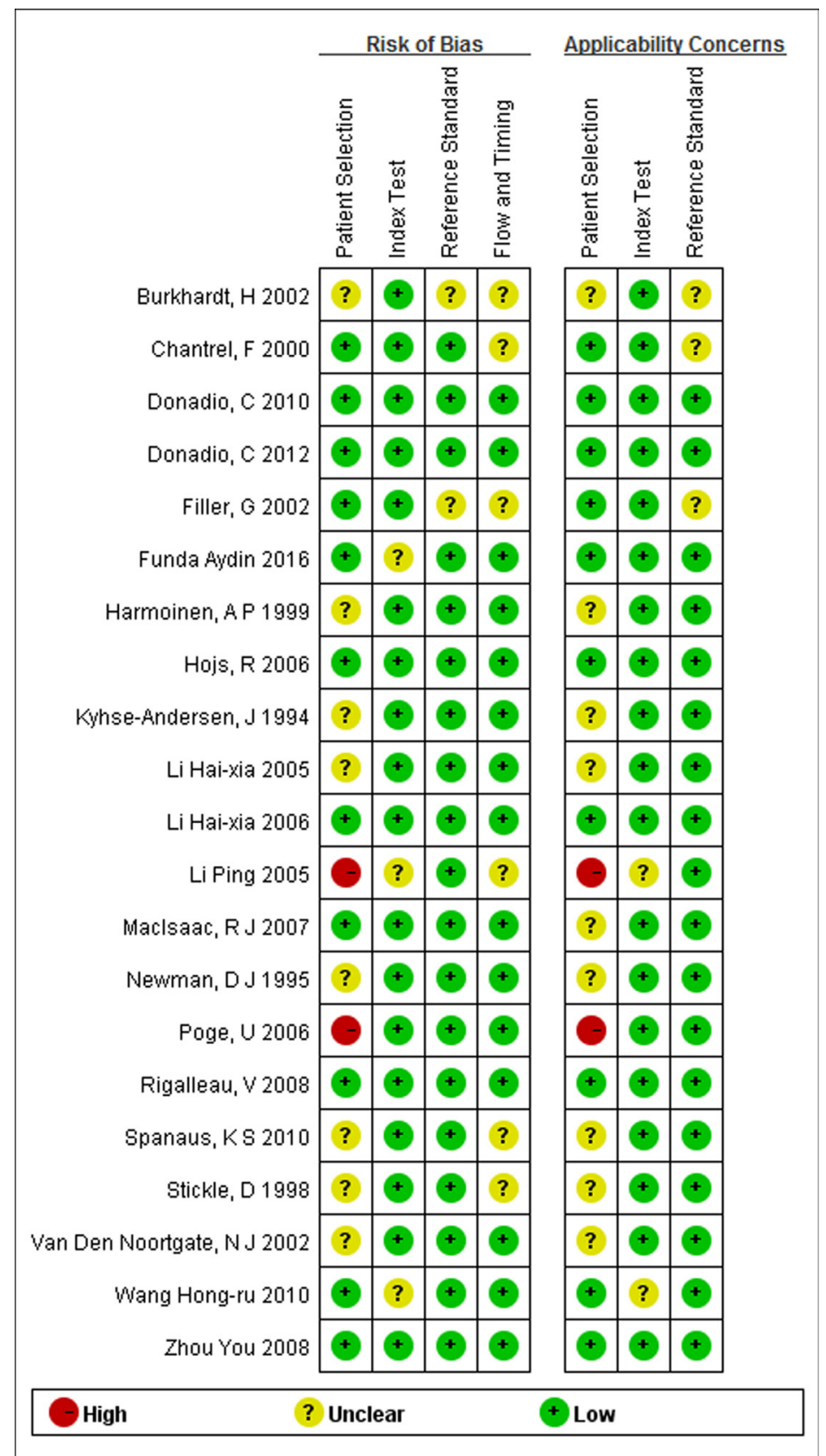

Figure 2: Results of the evaluation of each study according to QUADAS-2. See the colors in the online version.

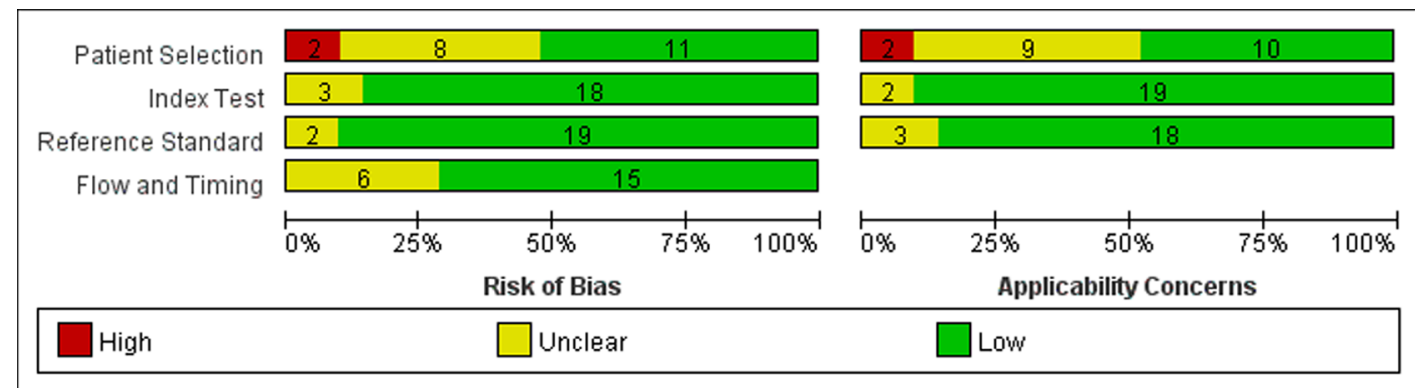

Figure 3: Methodological quality assessment summary by QUADAS-2. 
properties: release into the blood stream at a steady speed, free filtration by the glomerulus, no reabsorption or secretion by the renal tubules, and removal through the kidneys [28]. Most research mentions many factors that effect the generation of $\mathrm{SCr}$, including age, gender, muscle mass, pharmaceutical or other drug use, among others. In addition, until kidney function loss has reached 50\%, a typical concentration of SCr may be seen due to tubular secretion and additional clearance through the viscera [29].
$\mathrm{SCr}$, urine creatinine, serum albumin or SCysC are most often used in eGFR assays [30]. GFR may be calculated via many formulas, and all of these assays and equations were found in the included studies. However, as no single method has been validated in a large human population of CKD patients, finding the best method to assess renal function in CKD patients that can be carried out in routine practice is a problem that needs to be addressed. $\mathrm{SCr}$ is suggested to be the typical indicator

\section{A}

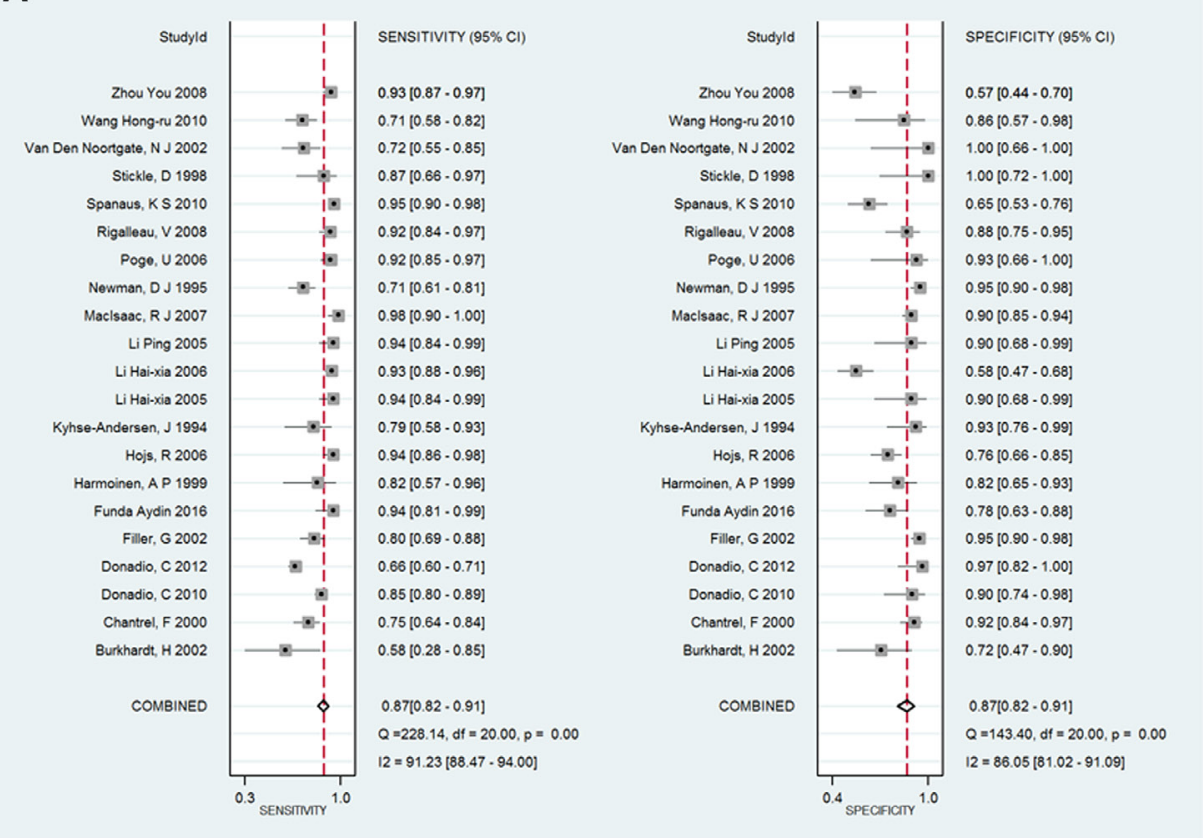

B

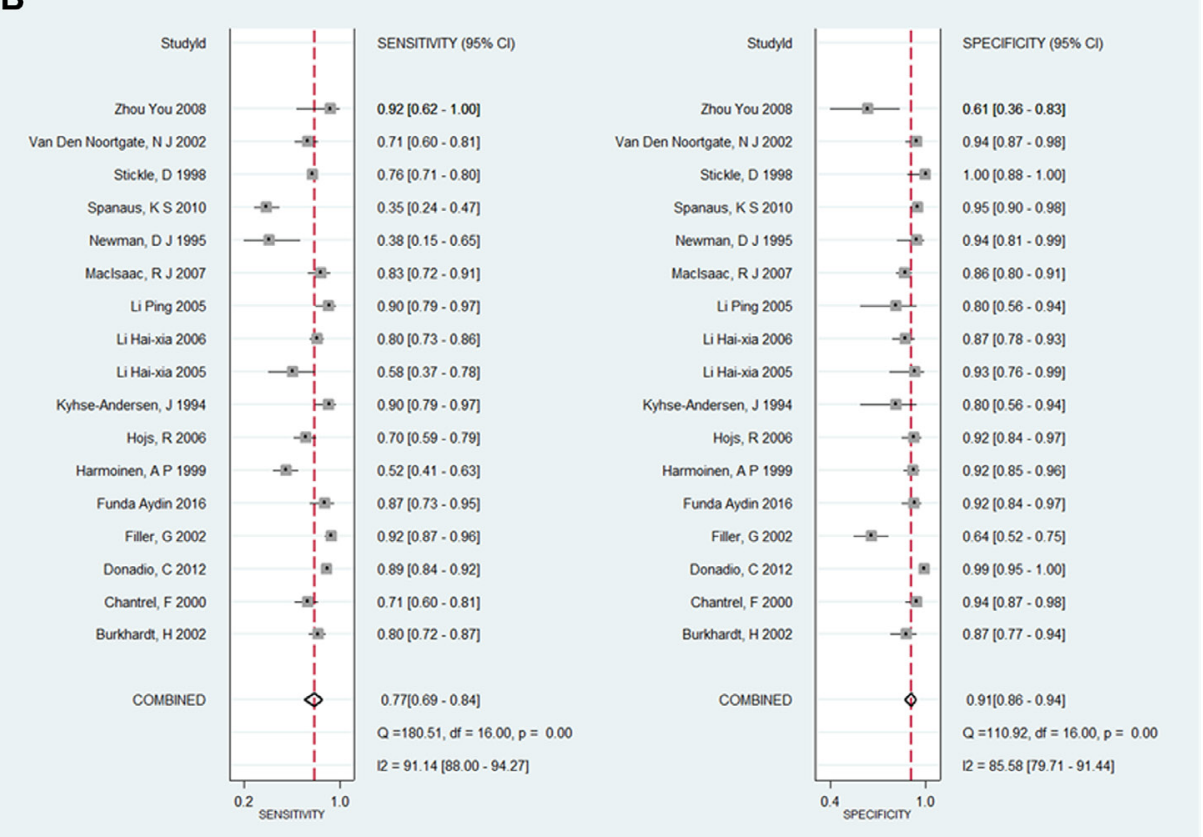

Figure 4: (A) The forest plot of sensitivity and specificity for SCysC in evaluating eGFR. (B) The forest plot of sensitivity and specificity for $\mathrm{SCr}$ in evaluating eGFR. 
for renal injury assessment, and plays a significant clinical role in the evaluation of GFR in patients with chronic kidney disease. Additionally, about five to ten percent of discharged creatinine comes from distal tubule discharge, which more or less increases in answer to reduced GFR, making it difficult to accurately identify tiny and mild changes in GFR [31]. Drug treatments such as trimethoprim, cimetidine, cefoxitin that block the distal tubule from releasing creatinine can also enhance the SCr level, leading to increased bias in the estimation of GFR [32]. Normally, in kidney, the glomerulus filters creatinine and the tubule secrets creatinine. However, the secretion of the creatinine can be neglected when the GFR is significantly high [42]. A reported disadvantage of using creatinine is that nearly $50 \%$ of the total kidney creatinine excretion is due to proximal tubular secretion, thereby affecting its accuracy in estimating kidney function [62].

Unlike SCr, SCysC is filtered and reabsorbed in the proximal tubules freely, is not secreted by the tubules, and does not rely on sex, race, muscle mass or age. The concentration of SCysC is found to be stable within certain inflammatory conditions and in other disorders of

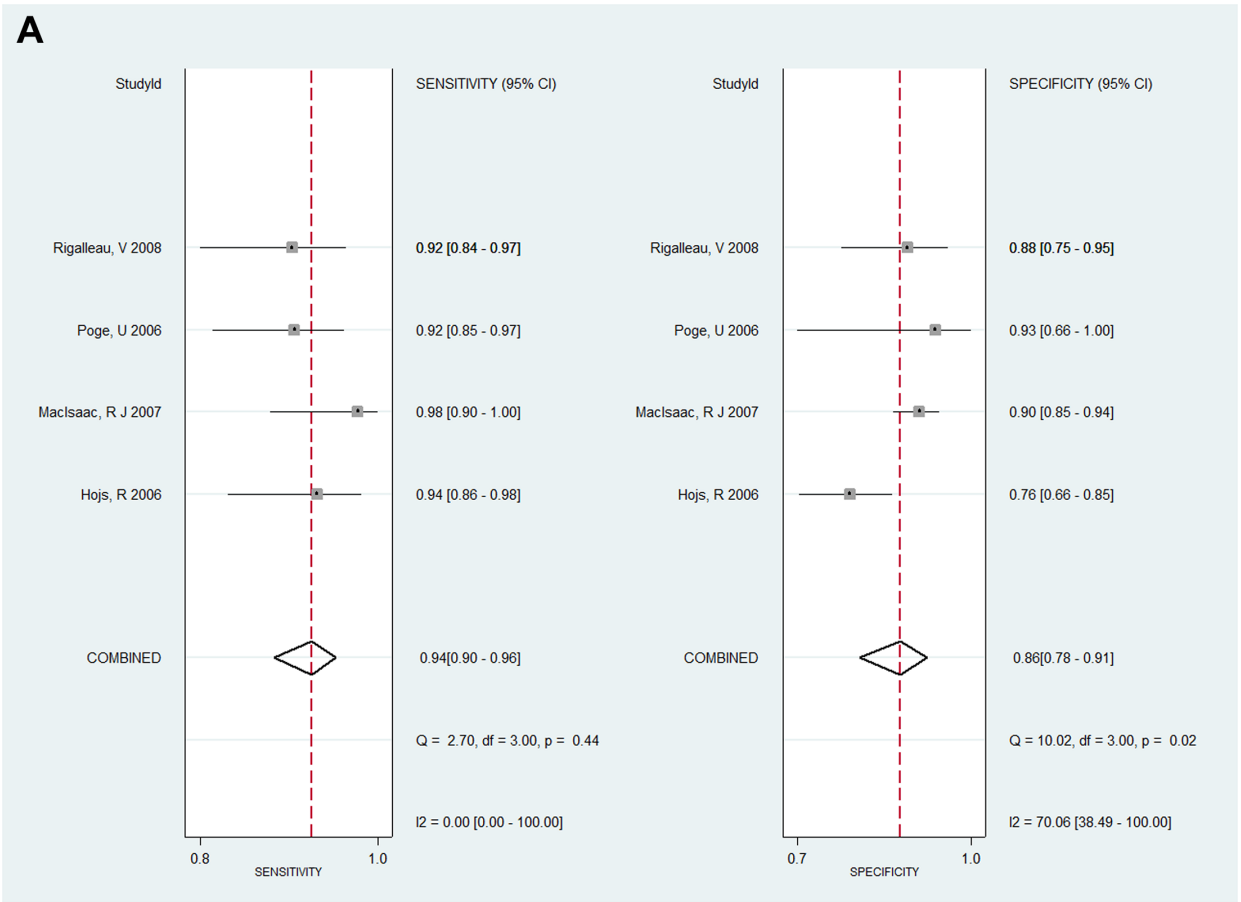

\section{B-1}

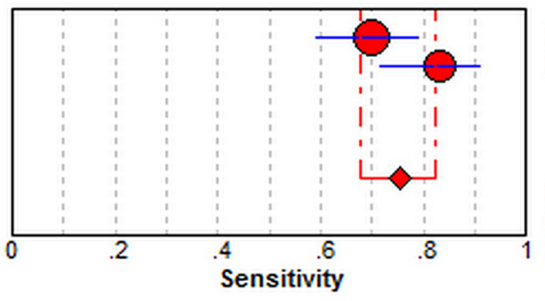

Hojs, R 2006

Maclsaac. R J 2007

Sensitivity $(95 \% \mathrm{CI})$

$0.70 \quad(0.59-0.79)$

$0.83(0.72-0.91)$

Pooled Sensitivity $=0.75(0.68$ to 0.82$)$

Chi-square $=3.65 ; \mathrm{df}=1(\mathrm{p}=0.0562)$

Inconsistency (l-square) $=72.6 \%$

\section{B-2}

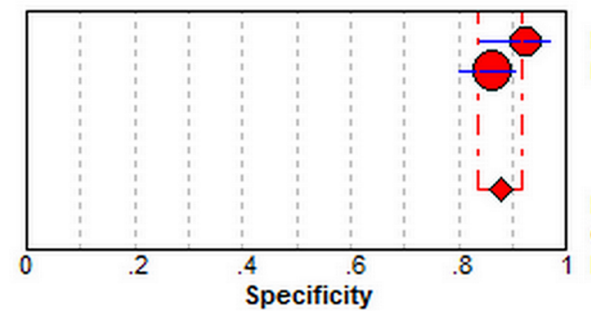

Specificity $(95 \% \mathrm{Cl})$

$0.92(0.84-0.97)$

$0.86(0.80-0.91)$

Maclsaac. R J 2007

Pooled Specificity $=0.88(0.83$ to 0.92$)$

Chi-square $=2.16 ;$ df $=1(p=0.1418)$

Inconsistency (l-square) $=53.7 \%$

Figure 5: (A) The subgroup analysis for SCysC when cut-off values as $60\left(\mathrm{~mL} / \mathrm{min} / 1.73 \mathrm{~m}^{2}\right)$, the forest plot of sensitivity and specificity for SCysC in evaluating eGFR. (B-1) The subgroup analysis for SCr when cut-off values as $60\left(\mathrm{~mL} / \mathrm{min} / 1.73 \mathrm{~m}{ }^{2}\right)$, the forest plot of sensitivity for $\mathrm{SCr}$ in evaluating eGFR. (B-2) The subgroup analysis for SCr when cut-off values as $60(\mathrm{~mL} / \mathrm{min} / 1.73 \mathrm{~m}$ ) , the forest plot of specificity for $\mathrm{SCr}$ in evaluating eGFR. 
A

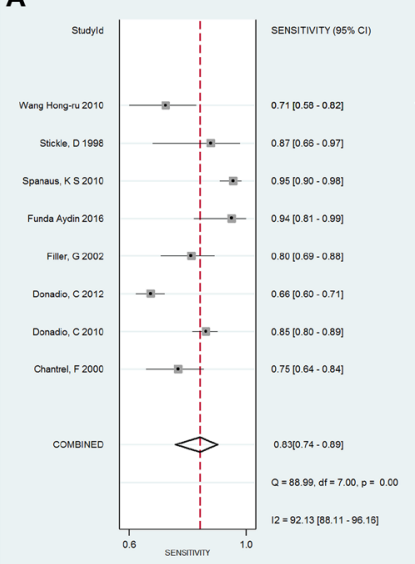

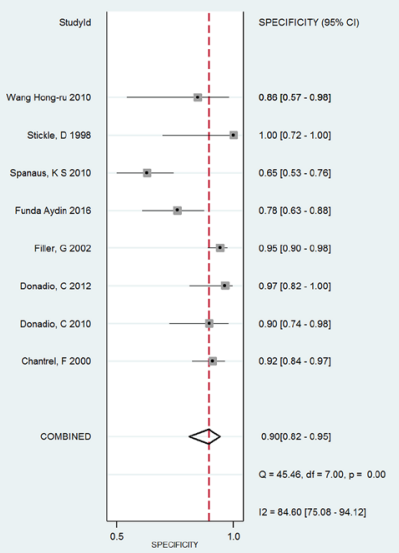

B

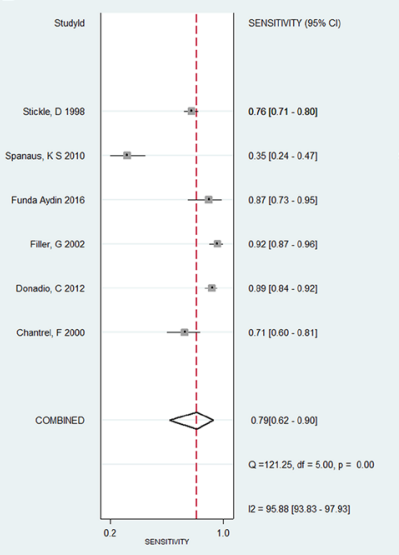

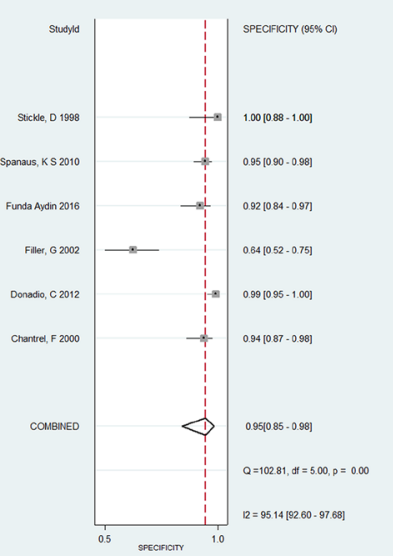

Figure 6: (A) The subgroup analysis for $\mathrm{SCysC}$ when cut-off values as $90\left(\mathrm{~mL} / \mathrm{min} / 1.73 \mathrm{~m}^{2}\right)$, the forest plot of sensitivity and specificity for SCysC in evaluating eGFR. (B )The subgroup analysis for $\mathrm{SCr}$ when cut-off values as $90\left(\mathrm{~mL} / \mathrm{min} / 1.73 \mathrm{~m}^{2}\right)$, the forest plot of sensitivity and specificity for $\mathrm{SCr}$ in evaluating eGFR.

A

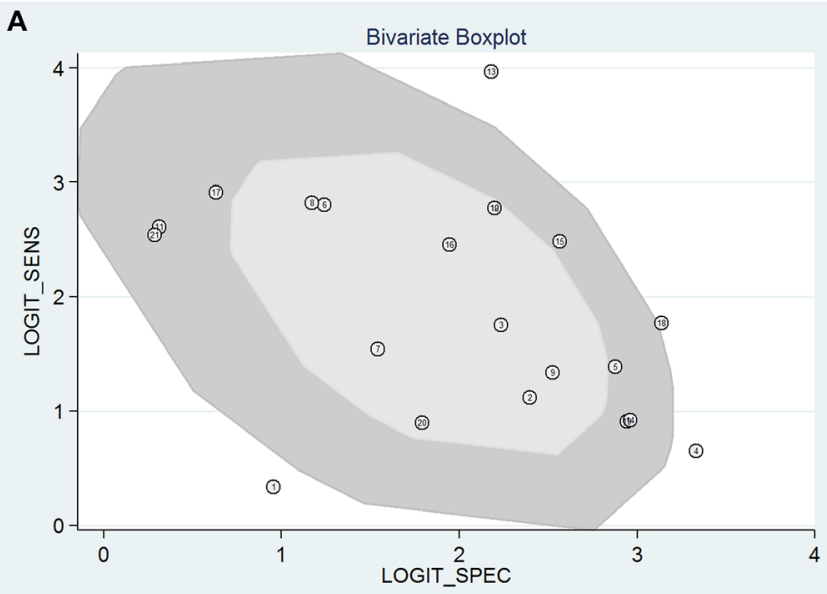

B

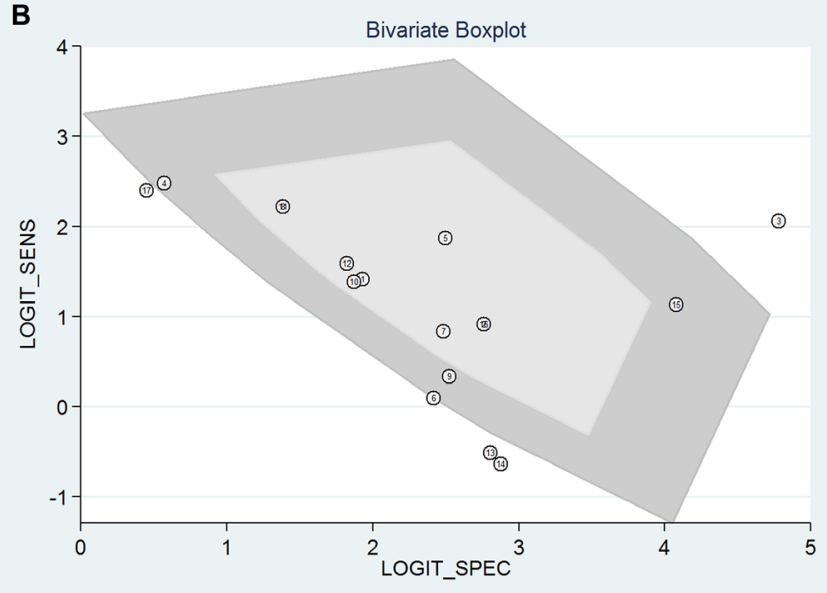

Figure 7: (A) Bivariate boxplot heterogeneity analysis of the SCysC detection; (B) Bivariate boxplot heterogeneity analysis of the SCr detection.
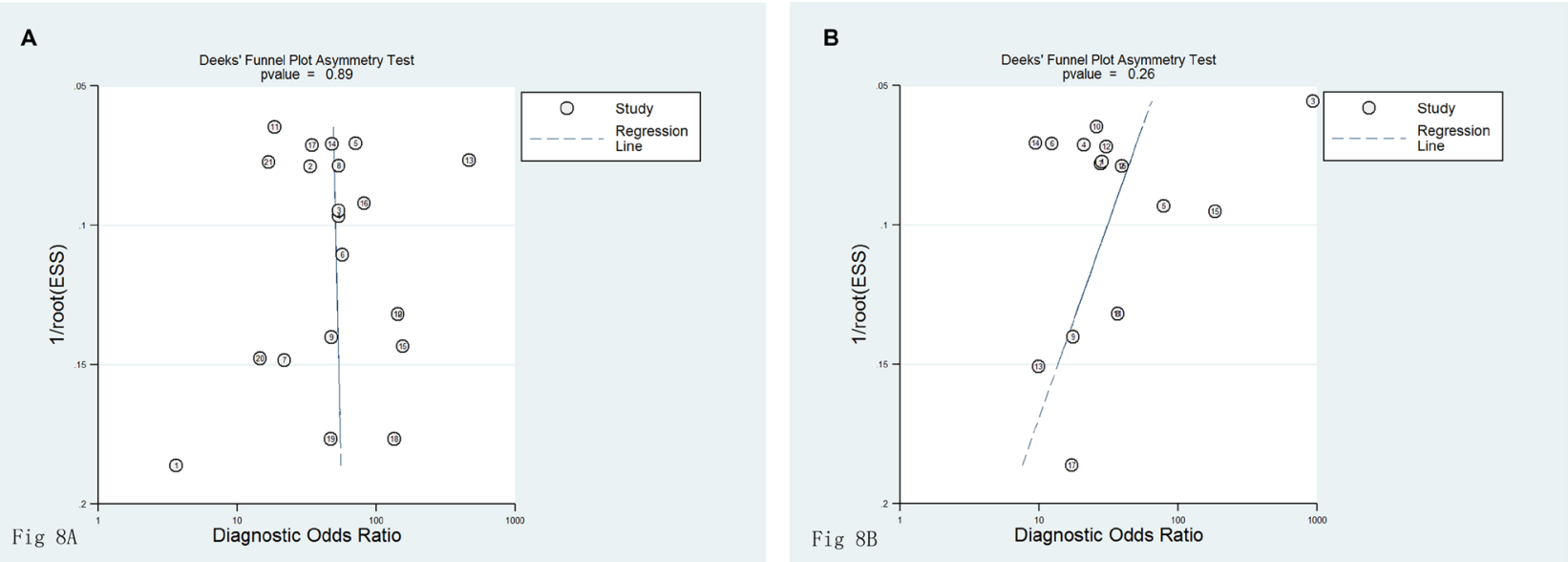

Figure 8: (A) Funnel plot of publication biasSCysC detection of studies included. (B) Funnel plot of publication bias for creatinine detection of studies included. 

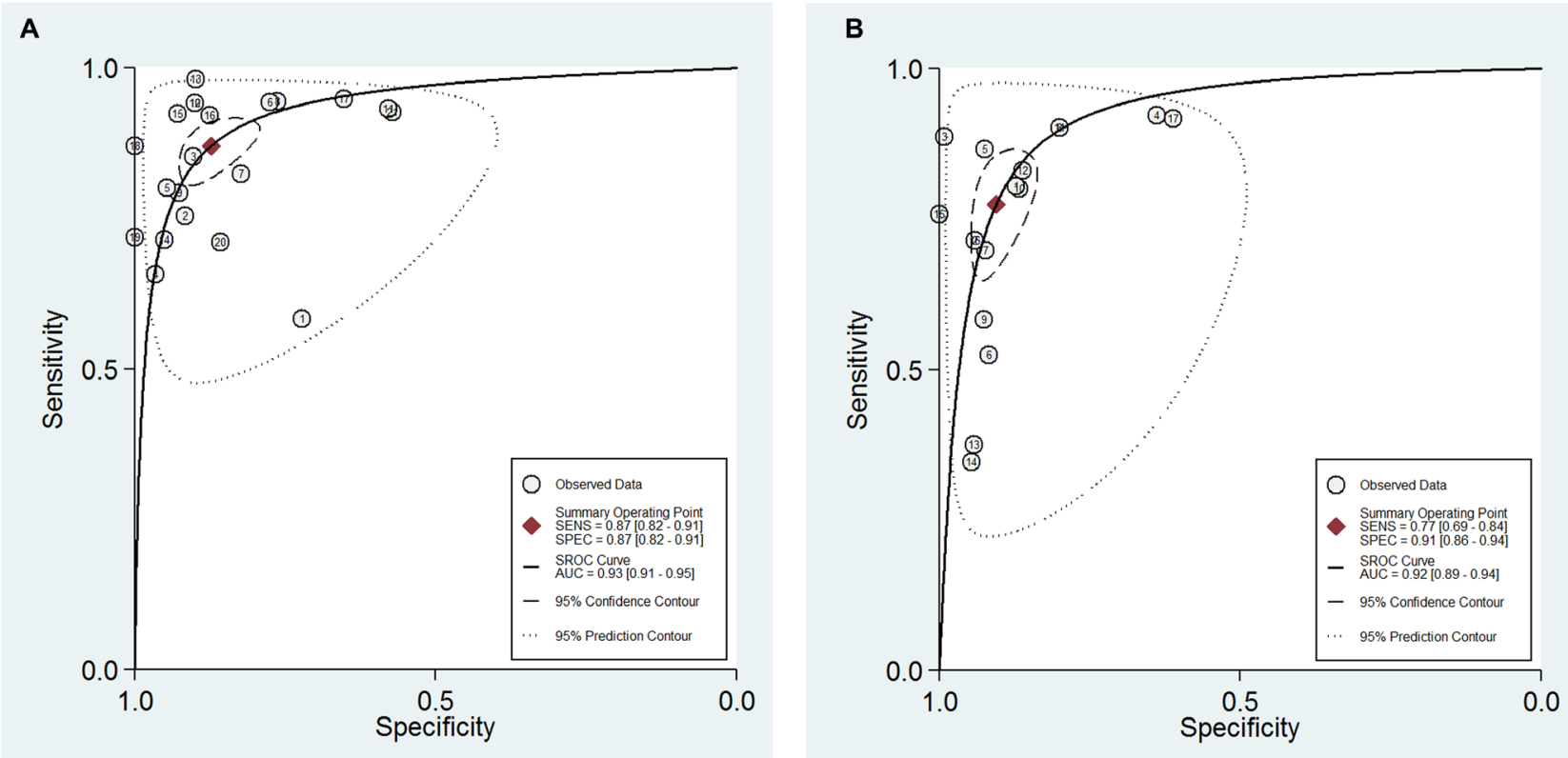

Figure 9: (A) SROC curve of the diagnostic value of GFR via SCysC. (B) SROC curve of the diagnostic value of GFR via SCr.
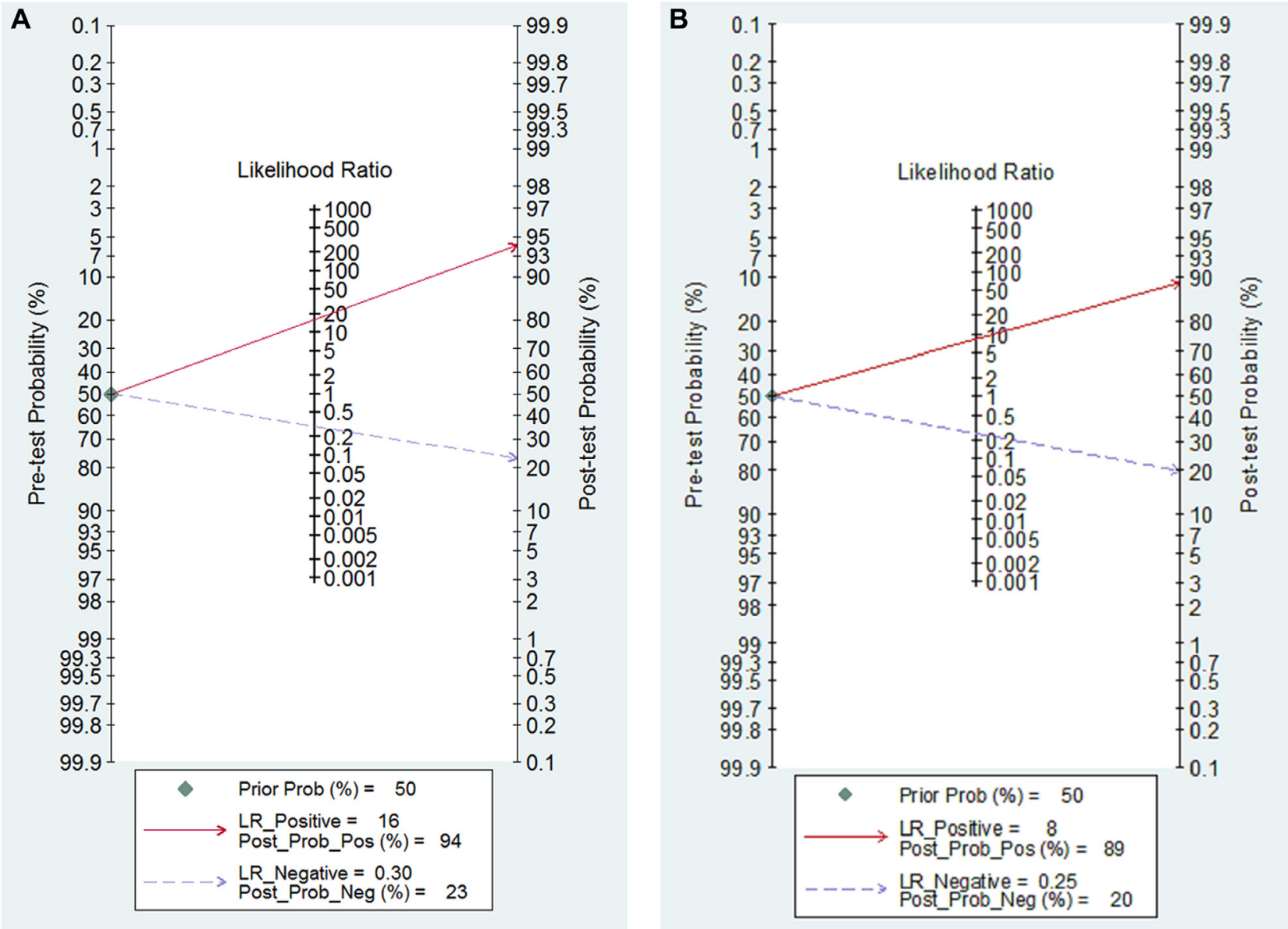

Figure 10: (A) Fagan's Nomogram of the SCysC test for diagnosis of eGFR. (B) Fagan's Nomogram of the SCr test for diagnosis of eGFR. 
metabolism. And it is possible to SCysC without a well documented limitation to the patients with extreme changes in weight, muscle mass. SCysC rises earlier than $\mathrm{SCr}$ when GFR declines, suggesting it could serve as a marker and have further benefits in detecting early renal dysfunction. SCysC has been shown to be better than SCr in GFR assessment, and its usefulness has been demonstrated in patients with almost regular kidney function. In previous studies within the general population and also in older people, SCysC has been shown to be an ideal predictor of death rate and major cardiovascular events, and has been reported to be better than SCr alone. Peralta et al. [31] studied 11,909 participants and found that SCysC levels in those cases may be useful for evaluating $\mathrm{CKD}$ individuals with high risk for complications. Including SCysC could enhance death risk forecast by phases of kidney function relative to SCr. The investigators found that comparison of associations using SCysC in estimating GFR can be used to indicate risk of hip fracture in older men. $\mathrm{SCysC}$ is produced by nucleated cells in all human beings and its concentration is not influenced by sex, age, dietary habit, swelling, etc. Hence, SCysC has no correlation with pathophysiological states other than GFR. This makes its expression an ideal endogenous marker in estimating GFR changes, and improves the accuracy of early diagnosis for kidney function. Therefore, SCysC provides reliable renal dysfunction risk prediction $[33,34]$.

A previous meta-analysis written by Shlipak et al. [35] demonstrated that it is possible that rearranging assessment of kidney function to include SCysC improved forecasts of the following: cardiovascular disease, renal morbidity, and mortality. Research by Coll et al. [36] showed that levels of SCr were raised in over $92.1 \%$ of patients that had reduced renal function in comparison with SCysC levels, which increased in every patient.

CKD patients or transplant patients should be categorized into stages based on their GFR. This has been suggested by the National Kidney Foundation Disease Outcomes Quality Initiative (K/DOQI) and by Kidney Disease Improving Global Outcomes (KDIGO) [37-40]. Risk of Progression in CKD is usually defined as impaired or decreased kidney function, with a GFR of less than $60 \mathrm{ml} / \mathrm{min}$ per $1.73 \mathrm{~m}^{2}$ for 3 months or longer, regardless of cause [37]. The results of our meta-analysis show that by SCysC-based estimates of the GFR, we may identify more latent CKD patients when cut-off values are $60\left(\mathrm{ml} / \mathrm{min} / 1.73 \mathrm{~m}^{2}\right)$, which is most important for secondary prevention of CKD progression. Therefore, we recommend that Cystatin C-based estimates of the GFR should universally be introduced into daily clinical practice or used as endpoints in clinical trials.

However, method limitations must be considered. Unpublished reports could not be identified, which might have biased our results. The aim of the present clinical research was to find an early, sensitive, specific indicator of GFR. In this research, we identified 21 articles to study and systematically performed a meta-analysis to determine the diagnostic value of GFR. The results demonstrated that the DORs of SCysC and SCr have a good correlation with GFR. Based on the forest plots for the degree of SEN and $\mathrm{SPE}$, the pooled effect of the SCysC and $\mathrm{SCr}$ values have apparent heterogeneity. Therefore, the likelihood ratio of SCysC has a stronger ability to judge kidney injury and exclude diagnostic effectiveness.

\section{CONCLUSIONS}

There is a significant association of eGFR with SCysC and SCr. Diagnostic accuracy for reduced renal function favors SCysC. The confidence intervals for the grouped sensitivity and specificity for $\mathrm{SCr}$ and $\mathrm{SCysC}$ intersect. However, SCysC was more sensitive for the estimation of GFR than SCr when the GFR cut-off values are set as $60\left(\mathrm{ml} / \mathrm{min} / 1.73 \mathrm{~m}^{2}\right)$. Estimating GFR based on $\mathrm{SCysC}$ concentration has not been studied extensively, but seems to be a promising method for evaluating the renal function of CKD patients. There is an urgent need for a wholesome prospective study using standardized creatinine assays, an appropriate gold standard and a population that factually represents the total population.

\section{Author contributions}

Conceived and designed the experiments: Wenbo Zhao, Xun Liu; Performed the experiments: Xilian Qiu, Chunyong Liu; Analyzed the data: Xilian Qiu, Chunyong Liu, Yuqiu Ye; Contributed reagents/materials/analysis tools: Xilian Qiu, Chunyong Liu, Huiqun Li, Yongmei Fu, Hongyong Liu, Yunqiang Zhang, Xueyuan Liao, Yanbing Chen; Wrote the paper: Xilian Qiu, Chunyong Liu.

\section{ACKNOWLEDGMENTS}

We wish to thank MBA Richard Clason for his revision of the English manuscript.

\section{CONFLICTS OF INTEREST}

\section{None.}

\section{FUNDING}

This study was supported by the National Natural Science Foundation of China (Grant No.81572088, $81303287,81601861,81370866$ and 81070612), the China Postdoctoral Science Foundation (Grant No. 201104335), Guangdong Science and Technology Plan (Grant No.2011B031800084, 2013B021800190, 2014A020212681, 2015A030313340), Guangdong Hospital of Traditional Chinese Medicine Science and Technology research subject Foundation(2014KT1593), the Fundamental Research Funds for the Central Universities (Grant No. 11ykpy38), 
the National Project of Scientific and Technical Supporting Programs Funded by Ministry of Science and Technology of China (Grant No. 2011BAI10B00), 'Twelfth five-year" national science and technology support project Foundation of China(2013KT1462 )

\section{REFERENCES}

1. Zhang QL, Rothenbacher D. Prevalence of chronic kidney disease in population-based studies: systematic review. BMC Public Health. 2008; 8:117-19. https://doi. org/10.1186/1471-2458-8-117.

2. Zhang L, Wang F, Wang L, Wang W, Liu B, Liu J, Chen M, He Q, Liao Y, Yu X, Chen N, Zhang JE, Hu Z, et al. Prevalence of chronic kidney disease in China: a crosssectional survey. Lancet. 2012; 379:815-22. https://doi. org/10.1016/S0140-6736(12)60033-6.

3. Go AS, Yang J, Ackerson LM, Lepper K, Robbins S, Massie BM, Shlipak MG. Hemoglobin level, chronic kidney disease, and the risks of death and hospitalization in adults with chronic heart failure: the Anemia in Chronic Heart Failure: Outcomes and Resource Utilization (ANCHOR) Study. Circulation. 2006; 113:2713-23. https://doi. org/10.1161/CIRCULATIONAHA.105.577577.

4. Kasiske BL, Vazquez MA, Harmon WE, Brown RS, Danovitch GM, Gaston RS, Roth D, Scandling JD, Singer GG, and American Society of Transplantation. Recommendations for the outpatient surveillance of renal transplant recipients. J Am Soc Nephrol. 2000 (Suppl 15); 11:S1-86.

5. Goerdt PJ, Heim-Duthoy KL, Macres M, Swan SK. Predictive performance of renal function estimate equations in renal allografts. Br J Clin Pharmacol. 1997; 44:261-65. https://doi.org/10.1046/j.1365-2125.1997.t01-1-00567.x.

6. Roos JF, Doust J, Tett SE, Kirkpatrick CM. Diagnostic accuracy of cystatin $\mathrm{C}$ compared to serum creatinine for the estimation of renal dysfunction in adults and children--a meta-analysis. Clin Biochem. 2007; 40:383-91. https://doi. org/10.1016/j.clinbiochem.2006.10.026.

7. Swedko PJ, Clark HD, Paramsothy K, Akbari A. Serum creatinine is an inadequate screening test for renal failure in elderly patients. Arch Intern Med. 2003; 163:356-60. https://doi.org/10.1001/archinte.163.3.356.

8. Gaygısız Ü, Aydoğdu M, Badoğlu M, Boyacı N, Güllü Z, Gürsel G. Can admission serum cystatin $\mathrm{C}$ level be an early marker subclinical acute kidney injury in critical care patients? Scand J Clin Lab Invest. 2016; 76:143-50. https:// doi.org/10.3109/00365513.2015.1126854.

9. Yassine HN, Trenchevska O, Dong Z, Bashawri Y, Koska J, Reaven PD, Nelson RW, Nedelkov D. The association of plasma cystatin $\mathrm{C}$ proteoforms with diabetic chronic kidney disease. Proteome Sci. 2016; 14:7-11. https://doi. org/10.1186/s12953-016-0096-7.

10. Mende C, Katz A. Cystatin C- and Creatinine-Based Estimates of Glomerular Filtration Rate in Dapagliflozin Phase 3 Clinical Trials. Diabetes Ther. 2016; 7:139-51. https://doi.org/10.1007/s13300-016-0158-y.
11. Lopez-Giacoman S, Madero M. Biomarkers in chronic kidney disease, from kidney function to kidney damage. World J Nephrol. 2015; 4:57-73. https://doi.org/10.5527/ wjn.v4.i1.57.

12. Diego E, Castro P, Soy D, Poch E, Nicolás JM. Predictive performance of glomerular filtration rate estimation equations based on cystatin $\mathrm{C}$ versus serum creatinine values in critically ill patients. Am J Health Syst Pharm. 2016; 73:206-15. https://doi.org/10.2146/ajhp140852.

13. Van Pottelbergh G, Van Heden L, Matheï C, Degryse J. Methods to evaluate renal function in elderly patients: a systematic literature review. Age Ageing. 2010; 39:542-48. https://doi.org/10.1093/ageing/afq091.

14. Inker LA, Schmid CH, Tighiouart H, Eckfeldt JH, Feldman HI, Greene T, Kusek JW, Manzi J, Van Lente F, Zhang YL, Coresh J, Levey AS, and CKD-EPI Investigators. Estimating glomerular filtration rate from serum creatinine and cystatin C. N Engl J Med. 2012; 367:20-29. https://doi. org/10.1056/NEJMoa1114248.

15. Rule AD, Bailey KR, Lieske JC, Peyser PA, Turner ST. Estimating the glomerular filtration rate from serum creatinine is better than from cystatin $\mathrm{C}$ for evaluating risk factors associated with chronic kidney disease. Kidney Int. 2013; 83:1169-76. https://doi.org/10.1038/ki.2013.7.

16. Ye X, Liu X, Song D, Zhang X, Zhu B, Wei L, Pei X, Wu J, Lou T, Zhao W. Estimating glomerular filtration rate by serum creatinine or/and cystatin $\mathrm{C}$ equations: an analysis of multi-centre Chinese subjects. Nephrology (Carlton). 2016; 21:372-78. https://doi.org/10.1111/nep.12636.

17. Emrich IE, Pickering JW, Schöttker B, Lennartz CS, Rogacev KS, Brenner H, Rothenbacher D, Holleczek B, Saum KU, Fliser D, Heine GH. Comparison of the performance of 2 GFR estimating equations using creatinine and cystatin $\mathrm{C}$ to predict adverse outcomes in elderly individuals. Am J Kidney Dis. 2015; 65:636-38. https:// doi.org/10.1053/j.ajkd.2014.12.006.

18. Fan L, Levey AS, Gudnason V, Eiriksdottir G, Andresdottir MB, Gudmundsdottir H, Indridason OS, Palsson R, Mitchell G, Inker LA. Comparing GFR Estimating Equations Using Cystatin C and Creatinine in Elderly Individuals. J Am Soc Nephrol. 2015; 26:1982-89. https://doi.org/10.1681/ ASN.2014060607.

19. James TJ, Lewis AV, Tan GD, Altmann P, Taylor RP, Levy JC. Validity of simplified protocols to estimate glomerular filtration rate using iohexol clearance. Ann Clin Biochem. 2007; 44:369-76. https://doi. org/10.1258/000456307780945804.

20. Brändström E, Grzegorczyk A, Jacobsson L, Friberg P, Lindahl A, Aurell M. GFR measurement with iohexol and 51Cr-EDTA. A comparison of the two favoured GFR markers in Europe. Nephrol Dial Transplant. 1998; 13:1176-82. https://doi.org/10.1093/ndt/13.5.1176.

21. O'Reilly PH, Brooman PJ, Martin PJ, Pollard AJ, Farah NB, Mason GC. Accuracy and reproducibility of a new contrast clearance method for the determination of glomerular 
filtration rate. Br Med J (Clin Res Ed). 1986; 293:234-36. https://doi.org/10.1136/bmj.293.6541.234.

22. Satirapoj B, Supasyndh O, Boonyavarakul A, Luesutthiviboon L, Choovichian P. The correlation of insulin resistance and renal function in non diabetic chronic kidney disease patients. J Med Assoc Thai. 2005 (Suppl 3); 88:S97-104.

23. Voskoboev NV, Larson TS, Rule AD, Lieske JC. Analytic and clinical validation of a standardized cystatin $\mathrm{C}$ particle enhanced turbidimetric assay (PETIA) to estimate glomerular filtration rate. Clin Chem Lab Med. 2012; 50:1591-96. https://doi.org/10.1515/cclm-2012-0063.

24. Allegaert K, Kuppens M, Mekahli D, Levtchenko E, Vanstapel F, Vanhole C, van den Anker JN. Creatinine reference values in ELBW infants: impact of quantification by Jaffe or enzymatic method. J Matern Fetal Neonatal Med. 2012; 25:1678-81. https://doi.org/10.3109/14767058 .2012 .657277 .

25. Whiting P, Rutjes AW, Reitsma JB, Bossuyt PM, Kleijnen J. The development of QUADAS: a tool for the quality assessment of studies of diagnostic accuracy included in systematic reviews. BMC Med Res Methodol. 2003; 3:25. https://doi.org/10.1186/1471-2288-3-25.

26. Whiting PF, Weswood ME, Rutjes AW, Reitsma JB, Bossuyt PN, Kleijnen J. Evaluation of QUADAS, a tool for the quality assessment of diagnostic accuracy studies. BMC Med Res Methodol. 2006; 6:9. https://doi. org/10.1186/1471-2288-6-9.

27. Balshem H, Helfand M, Schünemann HJ, Oxman AD, Kunz R, Brozek J, Vist GE, Falck-Ytter Y, Meerpohl J, Norris S, Guyatt GH. GRADE guidelines: 3. Rating the quality of evidence. J Clin Epidemiol. 2011; 64:401-06. https://doi. org/10.1016/j.jclinepi.2010.07.015.

28. Hsu CY, Propert K, Xie D, Hamm L, He J, Miller E, Ojo A, Shlipak M, Teal V, Townsend R, Weir M, Wilson J, Feldman H, and CRIC Investigators. Measured GFR does not outperform estimated GFR in predicting CKD-related complications. J Am Soc Nephrol. 2011; 22:1931-37. https://doi.org/10.1681/ASN.2010101077.

29. Slort PR, Ozden N, Pape L, Offner G, Tromp WF, Wilhelm AJ, Bokenkamp A. Comparing cystatin $\mathrm{C}$ and creatinine in the diagnosis of pediatric acute renal allograft dysfunction. Pediatr Nephrol. 2012; 27:843-49. https://doi.org/10.1007/ s00467-011-2073-9.

30. Stevens LA, Coresh J, Schmid CH, Feldman HI, Froissart M, Kusek J, Rossert J, Van Lente F, Bruce RD 3rd, Zhang YL, Greene T, Levey AS. Estimating GFR using serum cystatin $\mathrm{C}$ alone and in combination with serum creatinine: a pooled analysis of 3,418 individuals with CKD. Am J Kidney Dis. 2008; 51:395-406. https://doi.org/10.1053/j. ajkd.2007.11.018.

31. Mussap M, Plebani M. Biochemistry and clinical role of human cystatin C. Crit Rev Clin Lab Sci. 2004; 41:467550. https://doi.org/10.1080/10408360490504934.
32. Andreev E, Koopman M, Arisz L. A rise in plasma creatinine that is not a sign of renal failure: which drugs can be responsible? J Intern Med. 1999; 246:247-52. https://doi. org/10.1046/j.1365-2796.1999.00515.x.

33. Aksun SA, Ozmen D, Ozmen B, Parildar Z, Mutaf I, Turgan N, Habif S, Kumanlioğluc K, Bayindir O. Beta2microglobulin and cystatin $\mathrm{C}$ in type 2 diabetes: assessment of diabetic nephropathy. Exp Clin Endocrinol Diabetes. 2004; 112:195-200. https://doi.org/10.1055/s-2004-817933.

34. Dharnidharka VR, Kwon C, Stevens G. Serum cystatin C is superior to serum creatinine as a marker of kidney function: a meta-analysis. Am J Kidney Dis. 2002; 40:221-26. https:// doi.org/10.1053/ajkd.2002.34487.

35. Shlipak MG, Matsushita K, Ärnlöv J, Inker LA, Katz R, Polkinghorne KR, Rothenbacher D, Sarnak MJ, Astor BC, Coresh J, Levey AS, Gansevoort RT, and CKD Prognosis Consortium. Cystatin $\mathrm{C}$ versus creatinine in determining risk based on kidney function. N Engl J Med. 2013; 369:932-43. https://doi.org/10.1056/NEJMoa1214234.

36. Coll E, Botey A, Alvarez L, Poch E, Quintó L, Saurina A, Vera M, Piera C, Darnell A. Serum cystatin C as a new marker for noninvasive estimation of glomerular filtration rate and as a marker for early renal impairment. Am J Kidney Dis. 2000; 36:29-34. https://doi.org/10.1053/ ajkd.2000.8237.

37. Masson I, Maillard N, Cavalier E, Alamartine E, Mariat C, Delanaye P. KDIGO Guidelines and Kidney Transplantation: Is the Cystatin-C Based Recommendation Relevant? Am J Transplant. 2015; 15:2211-14. https://doi. org/10.1111/ajt.13258.

38. Akbari A, Clase CM, Acott P, Battistella M, Bello A, Feltmate P, Grill A, Karsanji M, Komenda P, Madore F, Manns BJ, Mahdavi S, Mustafa RA, et al. Canadian Society of Nephrology commentary on the KDIGO clinical practice guideline for CKD evaluation and management. Am J Kidney Dis. 2015; 65:177-205. https://doi.org/10.1053/j. ajkd.2014.10.013.

39. Levin A, Stevens PE. Summary of KDIGO 2012 CKD Guideline: behind the scenes, need for guidance, and a framework for moving forward. Kidney Int. 2014; 85:4961. https://doi.org/10.1038/ki.2013.444.

40. Lamb EJ, Levey AS, Stevens PE. The Kidney Disease Improving Global Outcomes (KDIGO) guideline update for chronic kidney disease: evolution not revolution. Clin Chem. 2013; 59:462-65. https://doi.org/10.1373/ clinchem.2012.184259.

41. Burkhardt H, Bojarsky G, Gladisch R. Diagnostic efficiency of cystatin $\mathrm{C}$ and serum creatinine as markers of reduced glomerular filtration rate in the elderly. Clin Chem Lab Med. 2002; 40:1135-38. https://doi.org/10.1515/cclm.2002.199.

42. Chantrel F, Agin A, Offner M, Koehl C, Moulin B, Hannedouche T. Comparison of cystatin $\mathrm{C}$ versus creatinine for detection of mild renal failure. Clin Nephrol. 2000; $54: 374-81$. 
43. Donadio C, Abdelkawy H, Grassi G. Echographic renal dimensions can predict glomerular filtration rate of potential living kidney donors. Transplant Proc. 2010; 42:1035-39. https://doi.org/10.1016/j.transproceed.2010.03.039.

44. Donadio C, Kanaki A, Caprio F, Donadio E, Tognotti D, Olivieri L. Prediction of glomerular filtration rate from serum concentration of cystatin C: comparison of two analytical methods. Nephrol Dial Transplant. 2012; 27:2826-38. https://doi.org/10.1093/ndt/gfs010.

45. Filler G, Priem F, Lepage N, Sinha P, Vollmer I, Clark $\mathrm{H}$, Keely E, Matzinger M, Akbari A, Althaus H, Jung K. Beta-trace protein, cystatin $\mathrm{C}$, beta(2)-microglobulin, and creatinine compared for detecting impaired glomerular filtration rates in children. Clin Chem. 2002; 48:729-36.

46. Aydin F, Budak ES, Demirelli S, Oner AO, Korkmaz S, Suleymanlar G, Akbas H, Davran F, Gungor F. Comparison of Cystatin C and $\beta$-Trace Protein Versus 99mTc-DTPA Plasma Sampling in Determining Glomerular Filtration Rate in Chronic Renal Disease. J Nucl Med Technol. 2015; 43:206-13. https://doi.org/10.2967/jnmt.115.154799.

47. Harmoinen AP, Kouri TT, Wirta OR, Lehtimäki TJ, Rantalaiho V, Turjanmaa VM, Pasternack AI. Evaluation of plasma cystatin $\mathrm{C}$ as a marker for glomerular filtration rate in patients with type 2 diabetes. Clin Nephrol. 1999; 52:363-70.

48. Hojs R, Bevc S, Ekart R, Gorenjak M, Puklavec L. Serum cystatin $\mathrm{C}$ as an endogenous marker of renal function in patients with mild to moderate impairment of kidney function. Nephrol Dial Transplant. 2006; 21:1855-62. https://doi.org/10.1093/ndt/gfl073.

49. Kyhse-Andersen J, Schmidt C, Nordin G, Andersson B, Nilsson-Ehle P, Lindström V, Grubb A. Serum cystatin $\mathrm{C}$, determined by a rapid, automated particle-enhanced turbidimetric method, is a better marker than serum creatinine for glomerular filtration rate. Clin Chem. 1994; 40:1921-26.

50. Li HX, Wu HH, Xu GB, Guo XH, Xia TA. [Comparison of serum Cystatin $\mathrm{C}$ and creatinine in the detection of glomeruli filtration function in diabetic patient]. Chin J Lab Med. 2005; 2005:602-605. [Article in Chinese].

51. Li HX, Zhang CL, Xu GB, Wang XJ, Li SK, Li ZY, Zhang $\mathrm{XC}, \mathrm{Xia}$ TA. [Reference values of serum Cystatin $\mathrm{C}$ and creatinine in healthy volunteers, and comparison of their evaluation of glomerular filtration function in chronic renal patients]. Chin J Lab Med. 2006; 2006:970-974. [Article in Chinese].

52. Li P. [Systematic review of cystatin $\mathrm{C}$ for indicating glomerular filtration function injury]. Chinese Lab Med. 2005; 2005:474-78. [Article in Chinese].

53. Macisaac RJ, Tsalamandris $\mathrm{C}$, Thomas MC, Premaratne E, Panagiotopoulos S, Smith TJ, Poon A, Jenkins MA, Ratnaike SI, Power DA, Jerums G. The accuracy of cystatin $\mathrm{C}$ and commonly used creatinine-based methods for detecting moderate and mild chronic kidney disease in diabetes. Diabet Med. 2007; 24:443-48. https://doi. org/10.1111/j.1464-5491.2007.02112.x.

54. Newman DJ, Thakkar H, Edwards RG, Wilkie M, White T, Grubb AO, Price CP. Serum cystatin C measured by automated immunoassay: a more sensitive marker of changes in GFR than serum creatinine. Kidney Int. 1995; 47:312-18. https://doi.org/10.1038/ki.1995.40.

55. Pöge U, Gerhardt T, Stoffel-Wagner B, Palmedo H, Klehr HU, Sauerbruch T, Woitas RP. Prediction of glomerular filtration rate in renal transplant recipients: cystatin $\mathrm{C}$ or modification of diet in renal disease equation? Clin Transplant. 2006; 20:200-05. https://doi.org/10.1111/ j.1399-0012.2005.00466.x.

56. Rigalleau V, Beauvieux MC, Le Moigne F, Lasseur C, Chauveau P, Raffaitin C, Perlemoine C, Barthe N, Combe C, Gin H. Cystatin $\mathrm{C}$ improves the diagnosis and stratification of chronic kidney disease, and the estimation of glomerular filtration rate in diabetes. Diabetes Metab. 2008; 34:482-89. https://doi.org/10.1016/j.diabet.2008.03.004.

57. Spanaus KS, Kollerits B, Ritz E, Hersberger M, Kronenberg F, von Eckardstein A, and Mild and Moderate Kidney Disease (MMKD) Study Group. Serum creatinine, cystatin $\mathrm{C}$, and beta-trace protein in diagnostic staging and predicting progression of primary nondiabetic chronic kidney disease. Clin Chem. 2010; 56:740-49. https://doi. org/10.1373/clinchem.2009.138826.

58. Stickle D, Cole B, Hock K, Hruska KA, Scott MG. Correlation of plasma concentrations of cystatin $\mathrm{C}$ and creatinine to inulin clearance in a pediatric population. Clin Chem. 1998; 44:1334-38.

59. Van Den Noortgate NJ, Janssens WH, Delanghe JR, Afschrift MB, Lameire NH. Serum cystatin C concentration compared with other markers of glomerular filtration rate in the old old. J Am Geriatr Soc. 2002; 50:1278-82. https:// doi.org/10.1046/j.1532-5415.2002.50317.x.

60. Wang H, Du G, Bao X. [Value of Serum Cystatin C in Evaluating Glomerular Filtration Rate in Patients with Chronic Kidney Disease]. Chinese Journal of Integrated Traditional and Western Nephrology. 2010; 2010: 421-423. [Article in Chinese].

61. Zhou Y. [Serum inhibition and used to evaluate the distribution of glomerular filtration rate of clinical studies in healthy people]. J Zhejiang Univ Eng Sci. 2008; 42:694-95. [Article in Chinese].

62. Rieg T. A High-throughput method for measurement of glomerular filtration rate in conscious mice. J Vis Exp. 2013; 75:e50330. 